\title{
Early Clinical Diagnosis of Falciparum Malaria Helps Reduction in Morbidity and Mortality among Children
}

\author{
Dr. Md. Jamshed Alam¹, Dr. Fakhrul Amin Badal ${ }^{2}$, Dr. Habiba Jesmin ${ }^{1}$, Dr. Most Monira Begum ${ }^{1}$, Dr. Noor Uddin
} Talukder $^{1}$, Dr. Nazmul Hossain ${ }^{1}$, Dr. Saiful Islam ${ }^{3}$

${ }^{1}$ Assistant Professor, Dept. of Child Health, Sheikh Hasina Medical College, Tangail, Bangladesh

${ }^{2}$ Resident Physician, 250 Beded General Hospital, Tangail, Bangladesh

${ }^{3}$ Assistant Register, 250 Beded General Hospital, Tangail, Bangladesh

DOI: $10.36347 /$ sjams.2020.v08i11.035

| Received: 06.11.2020 | Accepted: 18.11.2020 | Published: 23.11.2020

*Corresponding author: Dr. Md. Jamshed Alam

Abstract

Original Research Article

Total 100 cases of falciparum malaria, in the age group of 9 months to 12 years, were studied in the paediatric ward of Chittagong Medical College Hospital from March to August, 2003 with the objectives of studying the clinical presentations of falciparum malaria and their response to therapy, in children. Diagnosis of falciparum malaria was done by clinical examination as well as microscopical demonstration of Plasmodium falciparum in blood. Majority cases; 42 were within 4-6 years of age group, amongst them $61 \%$ were male and 39\% female. Majority cases $31 \%$ had malaria during the month of April $17 \%$ in May. Regarding regional distribution of patients, most of the patients came from Hill-tracts, Fatikchari 12\%, Rangunia 5\%, Cox'sbazar 16\% Chittagong 21\%. Presenting symptoms included fever $100 \%$, vomiting $15 \%$, headache $7 \%$, diarrhea $8 \%$, altered consciousness $28 \%$, respiratory distress $10 \%$, dark urine $14 \%$. Among febfile patients, clinicalstages was present, $29.1 \%$ percent cases developed cerebral malaria (10\%), pulmorary oedema $(21 \%)$ black-water fever signs, among complicated falciparum malaria were rise of temperature $(100 \%)$, pallor (69\%), hepatomegaly alone (56\%), splenomegaly alone (33\%), hepatosplenomegaly $23 \%$ and jaundice $22 \%$. Among 6 cases of cerebral malaria, Blantyre coma seale score 3 of more was observed in $78.5 \%$ cases and score $<3$ in $21.4 \%$ cases. The following signs were also observed: brisk tendon reflexes $2805 \%$, positive babinski's sign $21.4 \%$, convulsion $52 \%$ pulmonary oedema $7.2 \%$, abolished tendon reflexes $7.1 \%$ constricted pupil $7.1 \%$, nuchal stiffness $14.2 \%$, kernig's sign $7.1 \%$. Majority of patients $63 \%$ had parasite count $500-10,000$ their peripheral blood and count was plenty in only $2 \%$ cases. Most of the patients were anaemic but $13 \%$ cases had sever anaemia. Initial treatment was started with chloroquine in 6 cases, among them 4 cases showed parasite clearance in peripheral blood after 3days of treatment. The rest 2 patients having persistent parasitaemia were treated with quinine. Fresh 94 cases of cerebral malaria $(92+2=94$ cases) were treated with quinine therapy and these cases showed no parisitaemia in peripheral blood after treatment. Total survivors were 90 with 2 cases of residual change. But $10 \%$ patients died of cerebral malaria $(5 \%)$, black-water fever with renal failure $(3 \%)$, pulmonary oedema $(2 \%)$. In conclusion we can said that falciparum malaria is quite common in children in and around Chittagong district. Symptomatology of falciparum malaria in children is quite different from that of adults. Case can easily be diagnosed clinically and studying peripheral blood film.

Keywords: falciparum malaria, paediatric, microscopical demonstration, pulmonary oedema.

Copyright $\odot 2020$ The Author(s): This is an open-access article distributed under the terms of the Creative Commons Attribution 4.0 International License (CC BY-NC 4.0) which permits unrestricted use, distribution, and reproduction in any medium for non-commercial use provided the original author and source are credited.

\section{INTRODUCTION}

Malaria; a global health problem which affects more than $40 \%$ of the world population in 143 countries [1]. Over 300 millions of new malaria cases are added every year [2]. It kills more than one million people world wide each year and of these more than 15-25\% are under 5 children [3]. In South East Asia 9 countries out of 11 including Bangladesh are facing malarial health problem seriously. Main victims of this problem are children and pregnant women [4]. They are $75 \%$ of total affected people [2].

Falciparum malaria has got no particular characteristic clinical picture of its own and can be mimicked by a variety of febrile infectious illness in the tropics [5]. Severe malaria is falciparum malaria that is sufficiently serious to be an immediate threat to life. Occurs almost invariably as a result of delay in treating the uncomplicated malarial cases [1]. 
So there is a necessity to see the clinical presentations, response to anti-malarial therapy (before laboratory confirmation) and its outcome in children.

Considering WHO's focus on the clinical disease in its malaria control efforts there is a need for such data to guide diagnostic efforts in the absence of effective microscopy in highly endemic zone to start empirical treatment with antimalarial drug which significantly reduces morbidity and mortalilty due to falciparum malaria [6].

\section{OBJECTIVE}

\section{General Objective}

- The aim of current study is to early diagnosis of falciparum malaria from clinical presentations and early administration of treatment in the reduction of morbidity \& mortality.

\section{Specific Objective}

- To see the variable clinical presentations of falciparum malaria in children and response to therapy.

\section{METHODOLOGY}

Study type: It was a Prospective study.

Study place and period: At pediatric wards of Chittagong Medical College Hospital, Chittagong.

Study period: From March, 2003 to August, 2003.

Sampling method: Non-probability purposive sampling method was used to select sample population.

Study population: A total of 100 cases of falciparum malaria amoung 9 months to 12 years age group were included in the study.

\section{Procedure and Data Collection}

Data were collected by preformed semistructured questionnaire. Diagnosis of falciparum malaria was done by clinical examination as well as microscopic demonstration of asexual form of plasmodium in the blood film. Patients admitted with any suggestive symptoms of falciparum malaria clinically were examined for parasite in their peripheral blood at least twice. All cases were thoroughly examined clinically. Thick and thin films were prepared on slides from blood obtained by finger prick and daily parasite count were done by a pathologist in all the cases and in doubtful cases two separate pathologists examined the films. In addition to blood for $\mathrm{Mp}$, other laboratory evaluations were Total and differential leucocyte count, $\mathrm{Hb} \%$, Random blood glucose, unine analysis, serum electrolytes, BUN, serum creatinine, chest $\mathrm{X}$ - ray, serum bilirubin.

\section{ReSUlTS}

Table-1: Age distribution (N-100)

\begin{tabular}{|l|l|l|}
\hline Age (Years) & Number of Patients & Percentage (\%) \\
\hline 9m-11m & 11 & 11 \\
\hline $1-3$ Yrs. & 29 & 29 \\
\hline $4-6$ Yrs. & 42 & 42 \\
\hline 7-9 Yrs. & 14 & 14 \\
\hline $10-12$ Yrs. & 13 & 13 \\
\hline
\end{tabular}

Table- 1 shows that that $42 \%$ were in the $4-6$ years, $11 \%$ in the $9-11$ months age group. It is observed that younger adult are more sufferer than late adult.

Table-2: Sex distribution $(\mathrm{N}=100)$

\begin{tabular}{|l|l|l|}
\hline Sex & Number of patients & Percentage (\%) \\
\hline Male & 61 & 61 \\
\hline Female & 39 & 39 \\
\hline
\end{tabular}

In this study $61 \%$ male and $39 \%$ female, which is almost same as study done by "Kanti Parimal Nath. It is because of female population is still less than male in Bangladesh and female child is less cared in our socioeconomic culture.

Table-3: Month wise distribution on patients $(\mathrm{N}=100)$

\begin{tabular}{|l|l|l|}
\hline Months & Number of Patients & Percentage (\%) \\
\hline January & 5 & 5 \\
\hline February & 7 & 7 \\
\hline March & 19 & 19 \\
\hline April & 31 & 31 \\
\hline May & 17 & 17 \\
\hline June & 15 & 15 \\
\hline July & 5 & 5 \\
\hline August & 1 & 1 \\
\hline
\end{tabular}

Table-3 shows that cerebral malaria is more common in the May and June. In this series $31 \%$ in April, $14 \%$ in March, $17 \%$ in May and $15 \%$ in June. It may be due to yearly variation of rain-fall, temperature, and humidity. 
Table-4: Regional distribution. $(\mathrm{N}=100)$

\begin{tabular}{|l|l|l|}
\hline Region & Number of Patients & Percentage (\%) \\
\hline Rauzan & 4 & 4 \\
\hline Fatikchari & 12 & 12 \\
\hline Rangunia & 5 & 5 \\
\hline Chittagong Hilltracts (Rangamati, Bandarban, Khagrachari) & 24 & 24 \\
\hline Boalkhali & 3 & 3 \\
\hline Patia & 3 & 3 \\
\hline Chandanaish & 4 & 4 \\
\hline Banskhali & 4 & 4 \\
\hline Cox's bazar & 16 & 16 \\
\hline Ctg & 21 & 21 \\
\hline Satkania & 5 & 5 \\
\hline Other than ctg/Feni & 1 & 1 \\
\hline Sitakund & 1 & 1 \\
\hline
\end{tabular}

Here falciparum malaria has a firm root in Chittagong hill- tracts. In this study cases reported are from $24 \%$ from Hilltracts, $21 \%$ from Chittagong district.

Table-5: Features in cerebral Malaria $(\mathrm{N}=28)$

\begin{tabular}{|l|l|l|}
\hline Clinical Features observed & Number of Patient & Percentage (\%) \\
\hline Blantyre coma scale & & \\
Score: $<3$ & 6 & 21.42 \\
Score $: 3$ or more & 22 & 78.57 \\
\hline Convulsion & 16 & 57.14 \\
\hline Brisk tendon reflexes & 8 & 28.57 \\
\hline Planter extensor & 6 & 21.42 \\
\hline Absent reflexes & 2 & 7.14 \\
\hline Constricted pupil & 2 & 7.14 \\
\hline Deconjugate eye movement & 6 & 21.24 \\
\hline Decerebrate rigidity of Decorticate rigidity & 5 & 17.85 \\
\hline Nuchal residity & 4 & 14.2 \\
\hline Kernig's sign & 2 & 7.14 \\
\hline
\end{tabular}

Among 6 cases of cerebral malaria, Blantyre coma seale score 3 of more was observed in $78.5 \%$ cases and score $<3$ in $21.4 \%$ cases. The following signs were also observed: brisk tendon reflexes $2805 \%$, positive babinski's sign $21.4 \%$, convulsion $52 \%$ pulmonary oedema $7.2 \%$, abolished tendon reflexes $7.1 \%$ constricted pupil $7.1 \%$, nuchal stiffness $14.2 \%$, kernig's sign $7.1 \%$.

Table-6: Parasite density in peripheral blood on Admission ( $\mathrm{N}=100)$

\begin{tabular}{|l|l|l|}
\hline Parasite count per Milliliter of blood & Number of Patient & Percentage (\%) \\
\hline$<500$ & 8 & 8 \\
\hline $500-10,000$ & 63 & 63 \\
\hline $1000-50,000$ & 17 & 17 \\
\hline Infinity & 2 & 2 \\
\hline
\end{tabular}

Majority of patients $63 \%$ had parasite count 500-10,000 their peripheral blood and count was plenty in only $2 \%$ cases. Most of the patients were anaemic but $13 \%$ cases had sever anaemia. Leucoopenia was observed in 5\% leucocytosis in 39\% cases. Evidence of haemolysis was present in $22 \%$ cases; which included jaundice, severe anaemia $(\mathrm{Hb} \%=<5 \mathrm{~g} / \mathrm{dl})$, increased serum bilirubin level and reticulocytosis.

Table-7: Distribution of $\mathrm{HB}$ concentration $(\mathbf{N}=100)$

\begin{tabular}{|l|l|l|}
\hline $\mathbf{H b}(\mathbf{g m} / \mathbf{d l})$ & Number of Patient & Percentage $(\%)$ \\
\hline$<5$ & 13 & 13 \\
\hline $5-9$ & 42 & 42 \\
\hline $10-12$ & 31 & 31 \\
\hline$>12$ & 14 & 14 \\
\hline
\end{tabular}


Table-8: Total \& Differential count of WBC $(\mathrm{N}=100)$

\begin{tabular}{|l|l|l|}
\hline WBC & Number of Patient & Percentage (\%) \\
\hline$<4,000 /$ cu m. & 5 & 5 \\
\hline $4000-11,000 /$ ca m. & 77 & 77 \\
\hline$>11,000 /$ cu m. & 18 & 18 \\
\hline Monocytosis & 14 & 14 \\
\hline Lymphocytosis & 39 & 39 \\
\hline Normal D.C & 47 & 47 \\
\hline
\end{tabular}

In the present series, we found severe anaemia in $13 \%$ cases, moderate anaemia in $42 \%$ cases and mild anaemia in $3 \%$ cases. Here eucocytosis was in $18 \%$ cases, leucopenia in 5\% cases and normal leucocyte Count in $77 \%$ cases.

Table-9: CSF analysis

\begin{tabular}{|c|c|c|c|c|c|c|c|c|c|c|}
\hline \multirow[t]{2}{*}{ Parameters } & \multicolumn{10}{|c|}{ Case } \\
\hline & 1 & 2 & 3 & 4 & 5 & 6 & 7 & 8 & 9 & 10 \\
\hline Pressure & $\mathrm{N}$ & $\eta$ & $\mathrm{N}$ & $\mathrm{N}$ & $\mathrm{N}$ & $\eta$ & $\mathrm{N}$ & $\mathrm{N}$ & $\mathrm{N}$ & $\eta$ \\
\hline Colour & $\mathrm{C} 1$ & $\mathrm{C} 1$ & $\mathrm{C} 1$ & $\mathrm{C} 1$ & $\mathrm{C} 1$ & $\mathrm{C} 1$ & $\mathrm{C} 1$ & $\mathrm{C} 1$ & $\mathrm{C} 1$ & $\mathrm{C} 1$ \\
\hline $\begin{array}{l}\text { Cells (Normal 5/ ca m. } \\
\text { Lymphocyte }\end{array}$ & 10 & 08 & 05 & 12 & 9 & 11 & 10 & 14 & 08 & 06 \\
\hline Sugar normal $(40-80 \mathrm{mg} / .)$. & 35 & 45 & 40 & 50 & 45 & 60 & 45 & 35 & 60 & 40 \\
\hline Proteins (Normal 15-49mg/dl) & 30 & 35 & 40 & 30 & 40 & 30 & 40 & 45 & 35 & 40 \\
\hline
\end{tabular}

CSF were hazy in $11 \%$ percent cases. In the present series, we found CSF clear in all the cases of cerebral malaria, No significant changes in laboratory findings of CSF was observed.

Table-10: Outcome of patients with falciparum malaria after treatment.

\begin{tabular}{|l|l|l|}
\hline Out come & Number of patients & Percentage (\%) \\
\hline Survived & 90 & 90 \\
\hline Expired & 10 & 10 \\
\hline Cerebral malaria & 28 & 28 \\
\hline Blackwater fever & 9 & 9 \\
\hline Renal failure & 3 & 3 \\
\hline Residual change in the survivors & 2 & 2 \\
\hline
\end{tabular}

In the hospital 90\% survived without any residual changes and $10 \%$ died.

Table-11: Specific treatment $(\mathrm{N}=100)$

\begin{tabular}{|l|l|l|l|}
\hline $\begin{array}{l}\text { Initial } \\
\text { treatment } \\
\text { Started with }\end{array}$ & \multicolumn{2}{|l|}{ No Patients } & $\begin{array}{l}\text { Percentage of } \\
\text { Total patient } \\
(\%)\end{array}$ \\
\hline Chloroquine & Effective & Resistant & \multirow{2}{*}{6} \\
\cline { 2 - 4 } & 4 & 2 & 6 \\
\hline Quinine & 94 & - & 94 \\
\hline
\end{tabular}

\section{DISCUSSION}

Malaria is one of the tropical diseases against which WHO expressed its concern [7]. Malaria is considered as a severe health problem upon the people of Bangladesh since 1970. It is known as hyper endemic with its hilly areas. Younger age group is more vulnerable to the disease than adult. It is because of children are less immune or not immune. From a study by Hussain and Chakraborti $[9,10]$.

Sex distribution of patients in their study (Hussain and Chakraborty) was not representative. Because their study was on soldiers in Combined
Military Hospital most of the patients were natuarally male $[9,10]$. In my study $61 \%$ male and $39 \%$ female, which is almost same as study done by "Kanti Parimal Nath" [10]. It is because of female population is still less than male in Bangladesh and female child is less cared in our socio-economic culture.

In study on pediatric admission to Royal Victoria Hospital in Banjul, Brew ster showed that there is a marked variation on paediatric admission [11]. Which peaked following rainy season. Mortality of falciparum malaria is high in the rainy season than dry season. Rahman showed that cerebral malaria is more common in the May and June. In this series $31 \%$ in April, $14 \%$ in March, $17 \%$ in May and $15 \%$ in June. It may be due to yearly variation of rain-fall, temperature, and humidity [12].

Travelling history is an important clue in the diagnosis, mortality and morbidity of falciparum malaria. But no such travel history (From outside to endemic zone or staying outside for some period then back to endemic zone) was noted in this study. It is because of location of Chittagong Medical College 
Hospital. Where most of the patients are from bearby endemic zone. Migratory sufferers are brought to other hospitals. In one study by waiz mentioned that Falciparum malaria has a firm root in Chittagong hilltracts [13]. In this study cases reported are from $24 \%$ from Hilltracts, $21 \%$ from Chittagong district. This is more or less consistent with study of Waiz.

Patient with malaria developed normocytic norm chromic, sometimes hypochromic normocytic and very rarely macrocytic anemia. During a paroxysmal attack of fever, there may be leucocytosis. Later there is leucopenia with monocytosis and sometimes with monocytisis and sometimes with lymphocytosis [14]. In Hussain's study, he showed that $3 \%$ cases were severely anaemic, $7 \%$ patient had leucopenia, $78 \%$ had normal leucocyte count, $7 \%$ patient had leucocytosis, $43 \%$ patient had monocytosis, $27 \%$ patients had lymphocytosis. But in the present series, we found severe anaemia in $13 \%$ cases, moderate anaemia in $42 \%$ cases and mild anaemia in $3 \%$ cases. Here leucocytosis was in $18 \%$ cases, leucopenia in $5 \%$ cases and normal leucocyte Count in $77 \%$ cases.

This series also showed monocytosis in $14 \%$ cases and lymphocytosis in $39 \%$ cases. So, with some variability, most of the patients developed anaemia and some patients had leucopenia with lymphocytosis and monocytosis, which are consistent with former study.

Haemolysis is the commnest cause of anaemia in patients with falciparum malaria. In Hussain's study, $15 \%$ patients had evidence of haemolysis where only $4 \%$ cases had clinical jaundice. In the present series, $69 \%$ patient had evidence of haemolysis and luny $22 \%$ patients had clinical jaundice which are not consistent with former study. Here $47 \%$ of anaemia may be nutritional.

Faiz et al., showed that CSF were hazy in $11 \%$ percent cases [15]. In the present series, we found CSF clear in all the cases of cerebral malaria, No significant changes in laboratory findings of CSF was observed.

P. falciparum developed chloroquine resistance in African rural areas. In Thailand and Vietnam resistance to quinine is increasing [16]. In this study, in 96\% cases other than cerebral malaria initially were treated with chloroquine. On the $4^{\text {th }}$ day after treatment with chloroquine, 94\% patients showed clearance of parasite from peripheral blood. The remaining $2 \%$ patients of uncomplicated malaria were treated with quinine therapy. All patients were cleared of parasite from their peripheral blood. So, in our study, we observed $2 \%$ patients with falciparum malaria did not respond to chloroquine, but all patients on falciparum malaria responded to quinine therapy alone.

\section{CONCLUSION}

This analysis also states that the symptomatology of falciparum malaria in children differs from that of adults having very good response to early quinine therapy. So early suspicion of falciparum malaria in children with adequate quinine therapy can reduce unwanted mortality.

\section{REFERENCE}

1. Giles HM. Management of severe and complicated malaria; a practical hand book, WHO, Geneva, 1991.

2. Swasthya L. A health awareness journal of Chittagong Medical College Hospital. MRG Ctg.

3. Introducing the medicines for malaria venture, WHO information fact sheets; Back ground document, November 1999. WHO, 1211 Geneva 27 Switzerland, Phone:+41-22-791-3715.

4. Hiroshi Nakashima Dr. Director General WHO, 1992.

5. JCMCTA 1996: 7(5-3): 75-82 Malaria: New clinical case definition and treatment guideline.

6. Genton B, Smith T, Baea K, Narara A, Al-Yaman F, Beck HP, Hii J, Alpers M. Malaria: how useful are clinical criteria for improving the diagnosis in a highly endemic area?. Transactions of the Royal Society of Tropical Medicine and Hygiene. 1994 Sep 1;88(5):537-41.

7. Faiz A, Awal ARMA, Chowdhury SGM. Complication of falciparum malaria. J Bangladesh Col Phy Surg, 1985; 3:22-6.

8. Hussain, B. Presentation of plciparum malaria [Dissertation]. Dhaka: Bangladesh College of Physicians and Surgeons, 1987.

9. Chatterjee KD. Editor-Parasitology Protozoology, Helminthology. 12 $2^{\text {th }}$ edition, 1980. Reprint 1995. Calcutta-Chatteriee Medical Publication. 70-100.

10. Ohilip RE, Gilles HM. Malaria. IN: Medicine International (Bangladesh edition), 3. 1988:22205 .

11. Brewster DR, Greenwood BM. Seasonal variation of paediatric diseases in The Gambia, West Africa. Annals of tropical paediatrics. 1993 Jan 1;13(2):133-46.

12. Rahaman M. Cerebral malaria-study of 64 cases. Bangladsh Arm For Med J. 1991.

13. Ali L. Review of malaria in Bangladesh [Dissertation]. Dhaka: NIPSOM, 1987.

14. Khaleque AK. Editor, Practical Pathology (Clinical Pathology), $7^{\text {th }}$ ed. Dhaka, Bangladesh 1987; 468-88.

15. Faiz A, Awal ARMA, Chowdhury SGM, Complication of falciparum malaria. J Bangladesh Col Phy Surg 1985; 3;22-6.

16. Faiz MA. Crebral malaria- a study on 29 cases. Bangladesh Med J. 1996; 15. 